Research Article

\title{
Compact Wideband Circularly Polarized Antenna with Symmetric Parasitic Rectangular Patches for Ka-Band Applications
}

\author{
Rongling Jian (D, Yueyun Chen $(D$, and Taohua Chen (iD) \\ University of Science \& Technology Beijing, Xueyuan Road 30, Haidian District, Beijing, China \\ Correspondence should be addressed to Yueyun Chen; chenyy@ustb.edu.cn
}

Received 28 April 2019; Revised 21 August 2019; Accepted 21 September 2019; Published 13 October 2019

Guest Editor: Sami Myllymäki

Copyright (c) 2019 Rongling Jian et al. This is an open access article distributed under the Creative Commons Attribution License, which permits unrestricted use, distribution, and reproduction in any medium, provided the original work is properly cited.

\begin{abstract}
In this paper, a novel wideband circularly polarized (CP) millimeter wave (mmWave) microstrip antenna is presented. The proposed antenna consists of a central patch and a microstrip line radiator. The CP radiation is achieved by loading a rectangular slot on the ground plane. To improve the $3-\mathrm{dB}$ axial ratio bandwidth (ARBW), two symmetric parasitic rectangular patches paralleled to a central patch and a slit positioned to the right of the central patch are loaded. To verify this design, the proposed antenna is fabricated with a small antenna of $2.88 \times 3.32 \times 0.508 \mathrm{~mm}^{3}$. The measured impedance bandwidth (IMBW) for $\left|S_{11}\right|<-10 \mathrm{~dB}$ of the proposed antenna is $35.97 \%$ (22.8 to $33.8 \mathrm{GHz}$ ). Meanwhile, the simulation result shows that the 3 -dB ARBW is $15.19 \%$ (28.77 to $33.5 \mathrm{GHz})$ within impedance bandwidth, and the peak gain is from 5.08 to $5.22 \mathrm{dBic}$ within 3-dB ARBW. The proposed antenna is suitable for $\mathrm{CP}$ applications in the Ka-band.
\end{abstract}

\section{Introduction}

With the rapid development of the 5th generation (5G) wireless communication, circularly polarized $(\mathrm{CP})$ antennas have received increasing attention because they can overcome multipath interferences, polarization mismatch, and Faraday rotation effects [1-5]. However, the study of bandwidth enhancement of the CP antenna in the Ka-band is an open issue.

In recent years, many technologies were proposed to enhance CP antenna bandwidth such as loading parasitic strips or protruding stub [6-9], loading slots or slits [10-13], and cavity model-based methodology $[14,15]$. Patch antennas with parasitic strips and ring patches are presented for wideband circular polarization [6,7]. Through protruding a horizontal stub from the ground plane, the $3-\mathrm{dB}$ axial ratio bandwidth (ARBW) is enhanced [8]. A hybrid Z-shaped cylindrical resonator antenna for multiband applications is proposed in [9]. Meanwhile, by loading a lightning-shaped slot for achieving good $\mathrm{CP}$ radiation, an annular-slot dualbroadband CP antenna is achieved [10]. The $3-\mathrm{dB}$ ARBW is enhanced by cutting a rectangular slit [11] and moving the feeding ports to the upper portion of the U-shaped slot [12].
To achieve $\mathrm{CP}$ radiation and antenna size reduction, an arrow-head-shaped slot is embedded in a square patch [13]. In addition, the $\mathrm{CP}$ antenna is designed by cavity model-based methodology. An omnidirectional dual-band dual-CP antenna with wide beam radiation patterns using $\mathrm{TM}_{01}$ and $\mathrm{TM}_{02}$ modes is investigated in [14]. A new CP antenna design method based cavity model-based methodology is proposed in [15].

To achieve a broadband $\mathrm{CP}$ antenna in mmWave, the aperture antenna [16-18], waveguide antenna [19], and patch antenna [20] are proposed. However, these antennas have more complex geometry, larger size, or higher loss at the feed network due to the resistors. In [16], a differentially fed CP planar aperture antenna is proposed for broadband $\mathrm{mmW}$ ave applications, and the $3-\mathrm{dB}$ ARBW is set to $16.7 \%$ (56 to $66.2 \mathrm{GHz}$ ) within its impedance bandwidth. The differentially driven planar aperture $\mathrm{CP}$ antenna is proposed to improve gain and expand the $3-\mathrm{dB}$ ARBW to $17.9 \%$ (56.5 to $67.5 \mathrm{GHz}$ ) [17]. The CP antenna is proposed through addition of a hybrid microstrip and elliptical dielectric ring resonator, and the $3-\mathrm{dB} A R B W$ is set to $10 \%$ (56 to $62 \mathrm{GHz}$ ) [18]. Due to many advantages, such as simple feeding, easy manufacture, precise control 


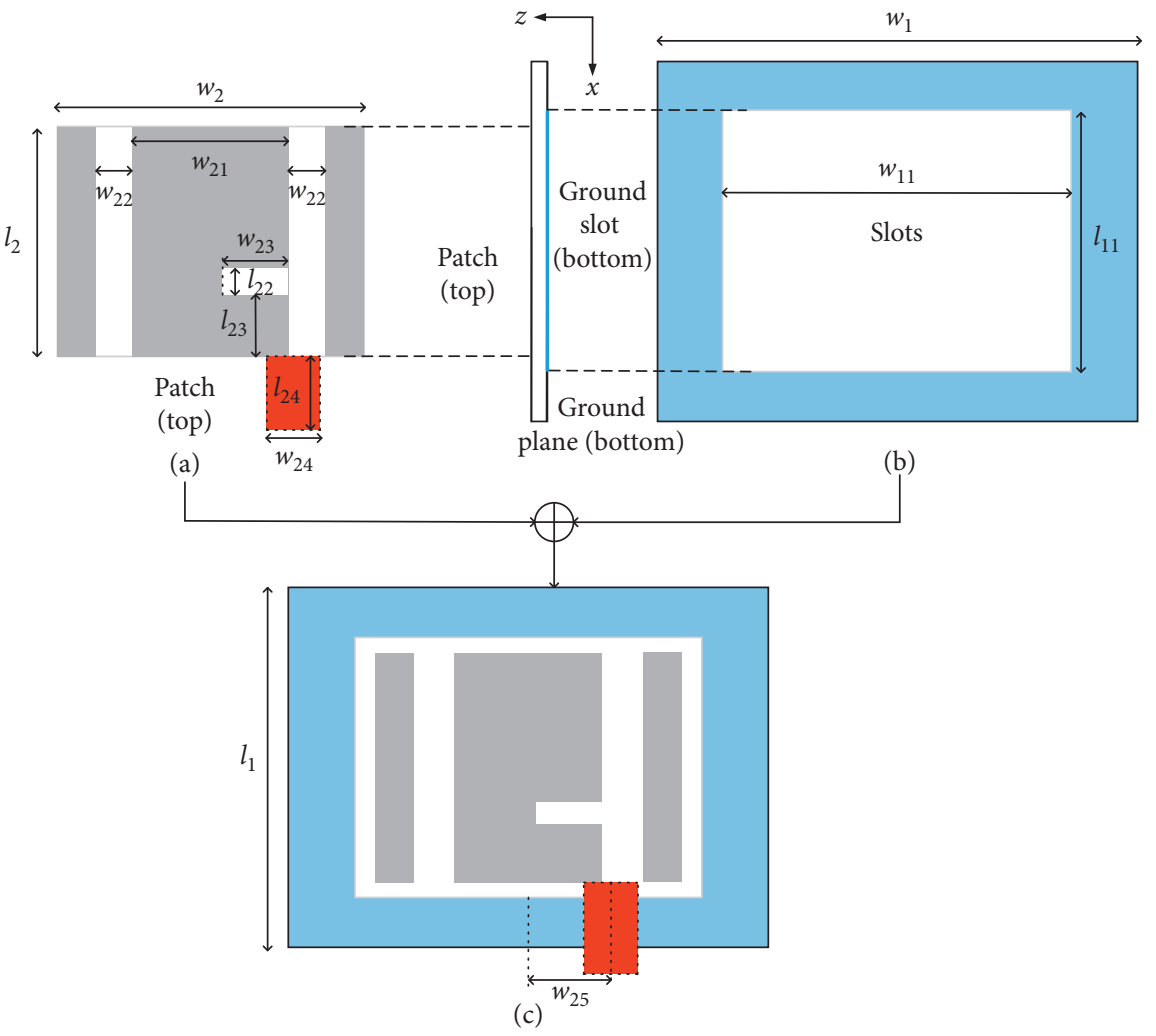

Figure 1: The geometries of the proposed CP antenna.

TABLE 1: The parameters of the proposed antenna structure.

\begin{tabular}{lc}
\hline Parameters & Value $(\mathrm{mm})$ \\
\hline$l_{1}$ & 5.76 \\
$w_{1}$ & 6.64 \\
$l_{11}$ & 3 \\
$w_{11}$ & 3.32 \\
$l_{2}$ & 2.88 \\
$w_{2}$ & 3.32 \\
$l_{22}$ & 0.26 \\
$l_{24}$ & 1.44 \\
$w_{21}$ & 1.84 \\
$w_{22}$ & 0.6 \\
$w_{23}$ & 0.75 \\
$w_{24}$ & 0.6 \\
$w_{25}$ & 0.8 \\
$l_{23}$ & 0.88 \\
\hline
\end{tabular}

of aperture distribution, and low loss, the slotted waveguide antenna has found wide applications in wireless communications. A CP waveguide antenna is presented for Ka-band applications [19]. The L-shaped patch and a tapered elliptical cavity CP antenna are proposed, and the $3-\mathrm{dB}$ ARBW is set to $11.9 \%(56.9$ to $64 \mathrm{GHz})$ [20].

The purpose of this paper is to develop a CP antenna with bandwidth enhancement, which can be used in a Kaband wireless communication system. With careful design of the rectangular slot on the ground plane, equal amplitude and $90^{\circ}$ phase difference between two orthogonal polarizations can be achieved, leading to a circular polarization at the design frequency. To enhance bandwidth of proposed antenna, two symmetric parasitic rectangular patches are loaded, which are parallel to the central patch, and a slit is loaded to the right of the central patch.

The remainder of this paper is organized as follows. Antenna design and analysis, including the proposed antenna structure, steps of the proposed antenna, and parameter studies, is described in Section 2. The antenna design results are presented in Section 3. Conclusion is drawn in Section 4.

\section{Antenna Design and Analysis}

2.1. Antenna Structure. The configuration of the proposed antenna is shown in Figure 1. This antenna is printed on a rectangular Rogers RT/Duroid 5880 substrate, where height $(h)$ is $0.508 \mathrm{~mm}$, dielectric constant $\left(\varepsilon_{r}\right)$ is 2.2 and dielectric loss tangent is 0.0009 . It consists of a microstrip line feeding port, ground plane with a rectangular slot, two parasitic rectangular patches, and a slit loaded in the central patch. The size of total patches is $l_{2} \times w_{2}=2.88 \times 3.32 \mathrm{~mm}^{2}$ [21]. The CP wave is generated by two orthogonal electric field vectors with equal amplitude and $90^{\circ}$ phase difference, which is mainly implemented by loading a rectangular slot on the ground plane. The $3-\mathrm{dB} A R B W$ is enhanced by loading two symmetric parasitic rectangular patches paralleled to the central patch and a slit positioned to the right of the central patch. The parameters of the proposed antenna are shown in Table 1. 


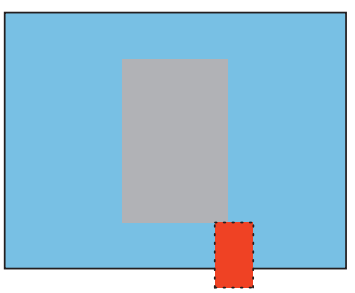

(a)

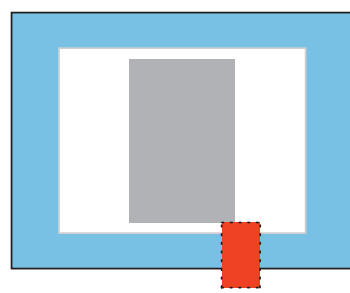

(b)

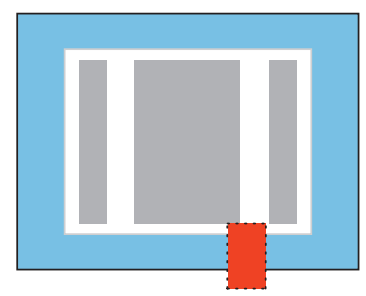

(c)

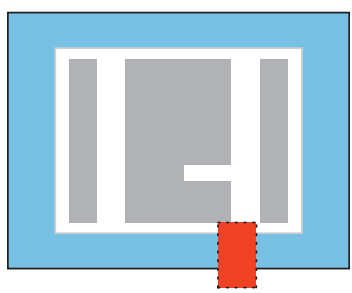

(d)

Figure 2: Steps to realize the proposed antenna. (a) ANT.1. (b) ANT 2. (c) ANT.3. (d) ANT.4.

2.2. Steps of the Proposed Antenna. The four antenna evolutions of the broadband Ka-band CP antenna are depicted in Figure 2 to explain the design process of bandwidth enhancement. In this paper, all the simulations are performed by Ansoft High Frequency Structure Simulator (version 13.0) based on the finite element method.

ANT.1 includes a basic rectangular patch and feed structure, which has received much attention in array applications [22]. As shown in Figure 3, ANT.1 has the disadvantage of narrow bandwidth, and it is linearly polarized (LP). In ANT.2, the CP radiation is achieved by loading a rectangular slot on the ground plane. Meanwhile, the impedance bandwidth (IBW) of ANT.2 is enhanced because input impedance is changed after loading the rectangular slot. However, the 3-dB AR bandwidth is poor. Wide ARBW is achieved by loading two symmetric parasitic rectangular patches paralleled to the central patch in ANT.3, and it is shown from Figure 4 that the $3-\mathrm{dB}$ ARBW is from 2.2 to 3.1 GHz. The ARBW is further enhanced by loading a small slit positioned to the right of the central patch in ANT.4. Figure 5 shows the simulated peak gain for ANT.1, ANT.2, and ANT.3 within the ARBW.

2.3. Parameter Studies. In order to clearly understand the design rules of the proposed antenna, a set of parameters, including the change in the width of rectangular slots on the patch $\left(w_{22}\right)$, the length of the slit $\left(w_{23}\right)$, and the feeding position $\left(w_{25}\right)$, will be discussed in this section. Meanwhile, the width of the central rectangular slot is decided by $w_{22}$. Note that when one parameter is studied, the other parameters are fixed as listed in Table 1.

By adjusting the width of rectangular slots on the patch $\left(w_{22}\right)$, the width of the central patch is also changed. As shown in Figure 6, the IMBW is expanded from 32.61\% $(23.48 \mathrm{GHz}$ to $31.46 \mathrm{GHz})$ to $35.42 \% \quad(24.11 \mathrm{GHz}$ to $34.49 \mathrm{GHz}$ ) with the increase of $w_{22}$ from 0.4 to $0.6 \mathrm{~mm}$. However, the IMBW is reduced with the increase of $w_{22}$ from 0.6 to $0.7 \mathrm{~mm}$. As shown in Figure 7, the 3 -dB ARBW is enhanced with the increase of $w_{22}$ from 0.4 to $0.6 \mathrm{~mm}$. However, ANT.4 becomes LP when $w_{22}$ is from 0.6 to $0.7 \mathrm{~mm}$. In this paper, we choose $w_{22}=0.6 \mathrm{~mm}$ for the proposed $\mathrm{CP}$ antenna design.

Figure 8 shows the simulated results of ANT.4 with the length of $w_{23}$ from 0.45 to $0.9 \mathrm{~mm}$. It can be seen from Figure 8 that the IMBW is increased as $w_{23}$ increases from 0 to $0.75 \mathrm{~mm}$. However, the IMBW is reduced with the increase of

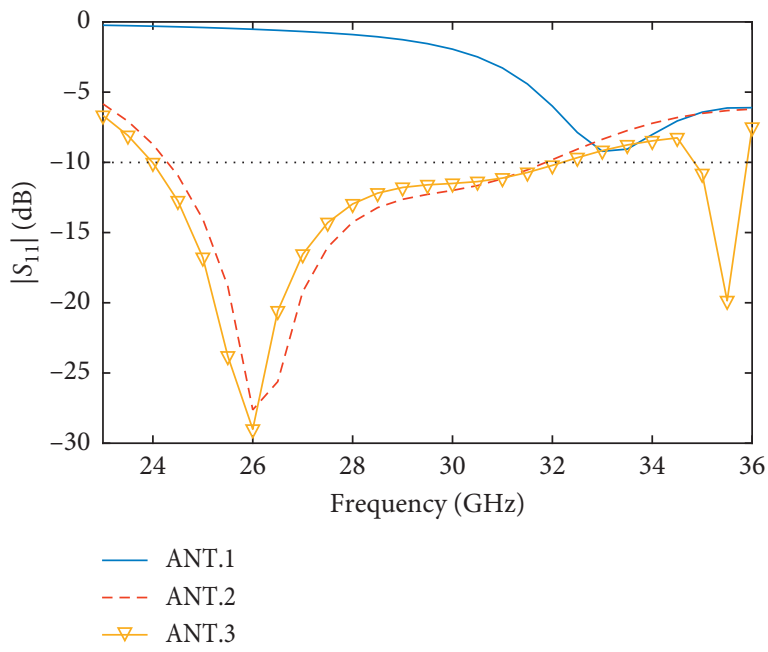

Figure 3: Simulated $S_{11}$ for ANT.1, ANT.2, and ANT.3.

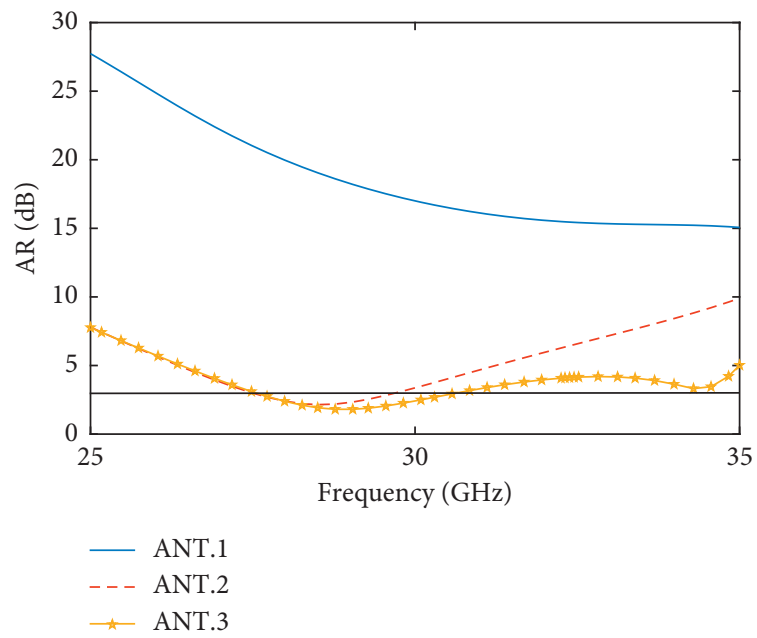

FIgURE 4: Simulated AR for ANT.1, ANT.2, and ANT.3.

$w_{23}$ from 0.75 to $0.9 \mathrm{~mm}$. Meanwhile, it can be seen from Figure 9 that the 3-dB ARBW is also increased as $w_{23}$ increases from 0.45 to $0.75 \mathrm{~mm}$. However, the IMBW is reduced with the increase of $w_{23}$ from 0.75 to $0.9 \mathrm{~mm}$. With the analysis above, we choose $w_{23}=0.75 \mathrm{~mm}$ for the proposed CP antenna design.

Through analysis, the effects of feeding position on impedance matching and feeding position $\left(w_{25}\right)$ can be decided. When the feeding position is studied, the other 


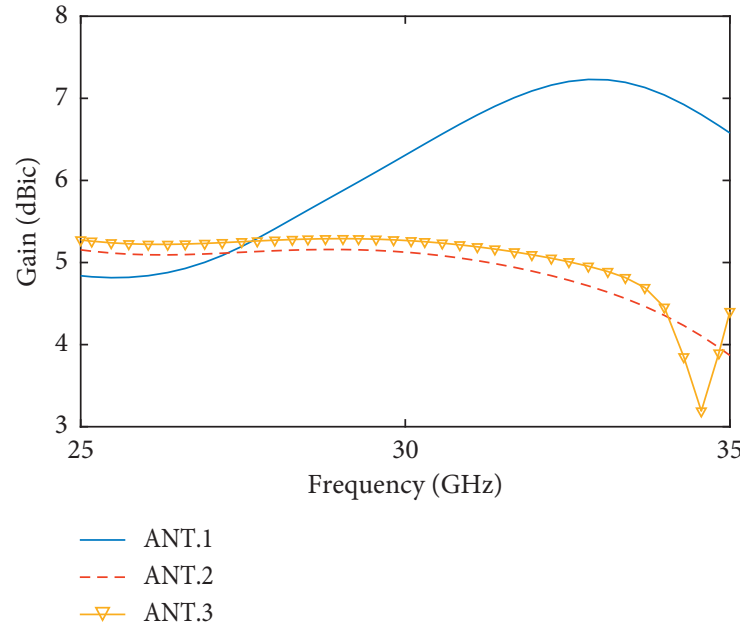

FIgUre 5: Simulated peak gain for ANT.1, ANT.2, and ANT.3.

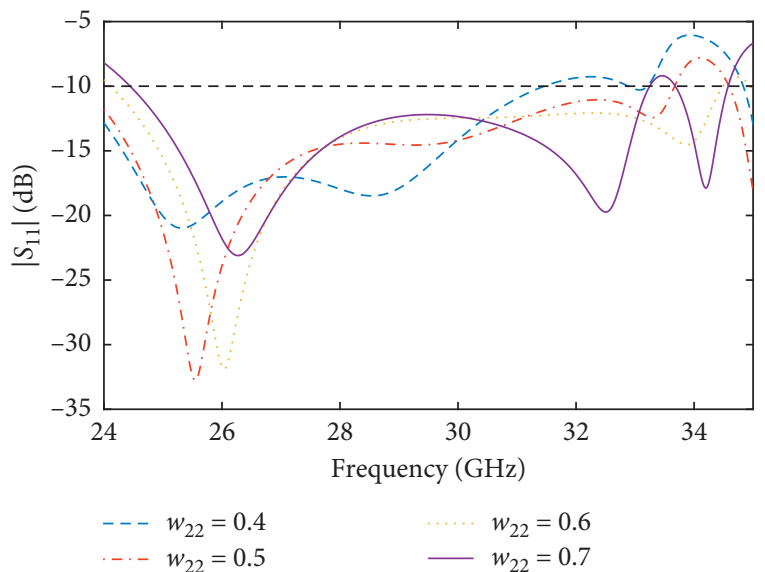

Figure 6: Effects of various $w_{22}$ on $S_{11}$.

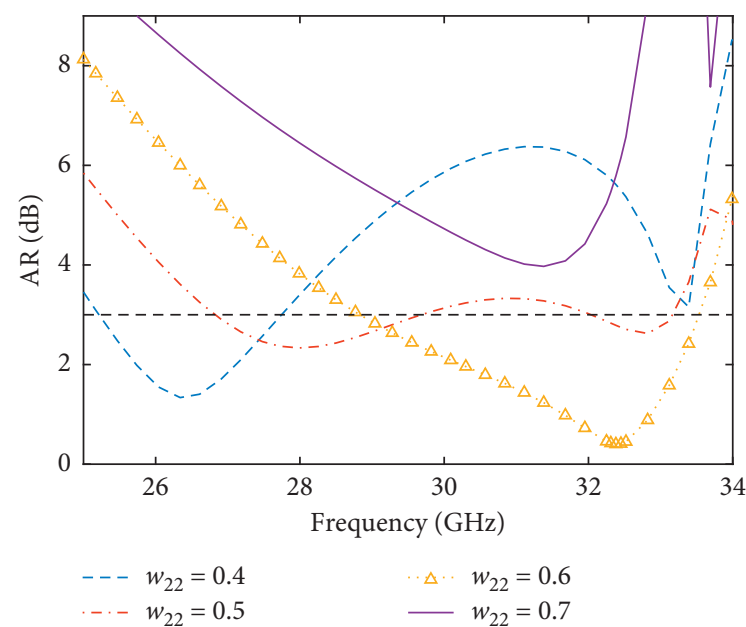

Figure 7: Effects of various $w_{22}$ on AR.

parameters are fixed as listed in Table 1. It is discovered from Figures 10 and 11 that it can achieve better impedance matching when $w_{25}$ is $0.8 \mathrm{~mm}$.

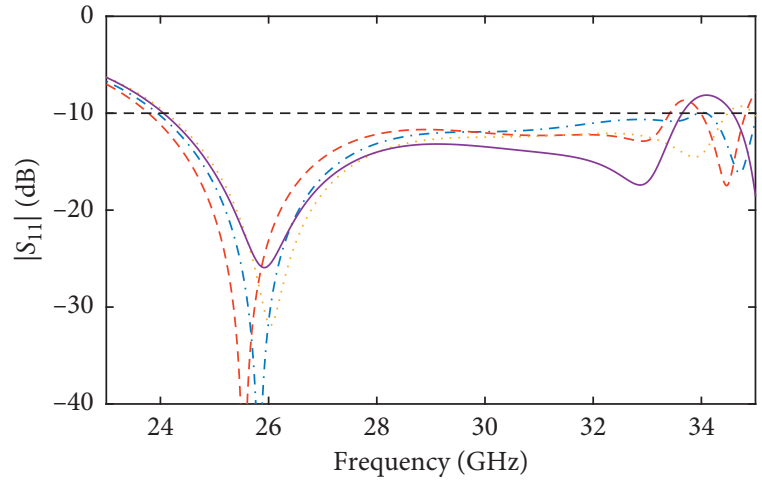

$$
\begin{aligned}
& \text { ‥ } w_{23}=0.45 \quad \cdots \cdots w_{23}=0.75 \\
& --w_{23}=0.6 \quad-w_{23}=0.9
\end{aligned}
$$

Figure 8: Effects of various $w_{23}$ on $S_{11}$.

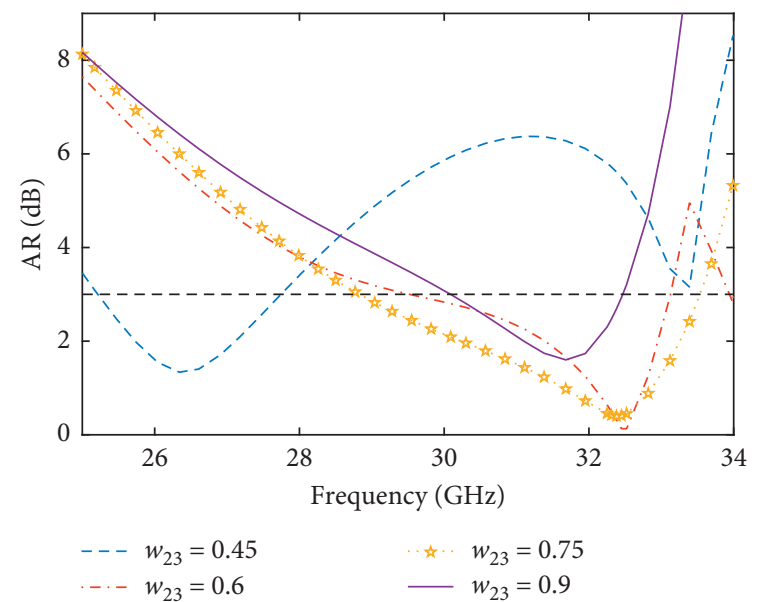

Figure 9: Effects of various $w_{23}$ on AR.

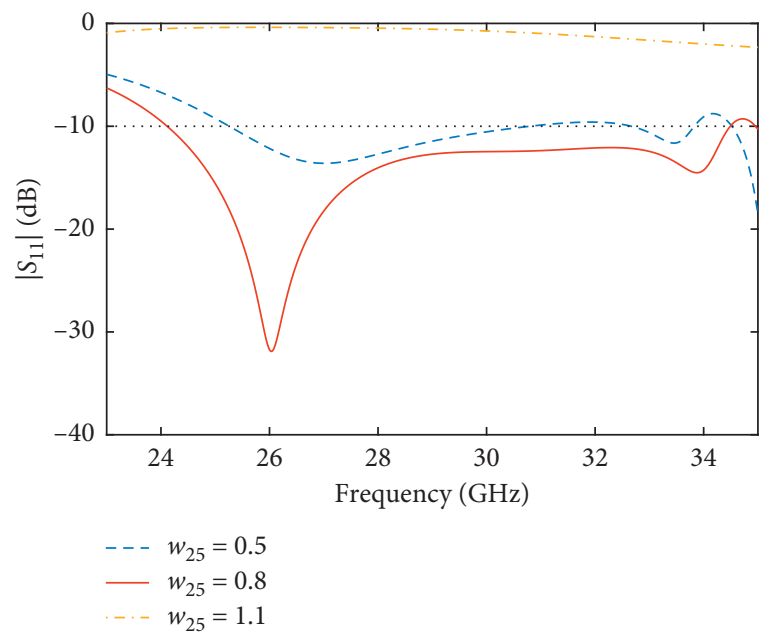

FIgURE 10: Effects of various $w_{25}$ on $S_{11}$.

\section{Design Results}

The final optimized antenna parameters are shown in Table 1. Based on the optimized parameters, the antenna is 


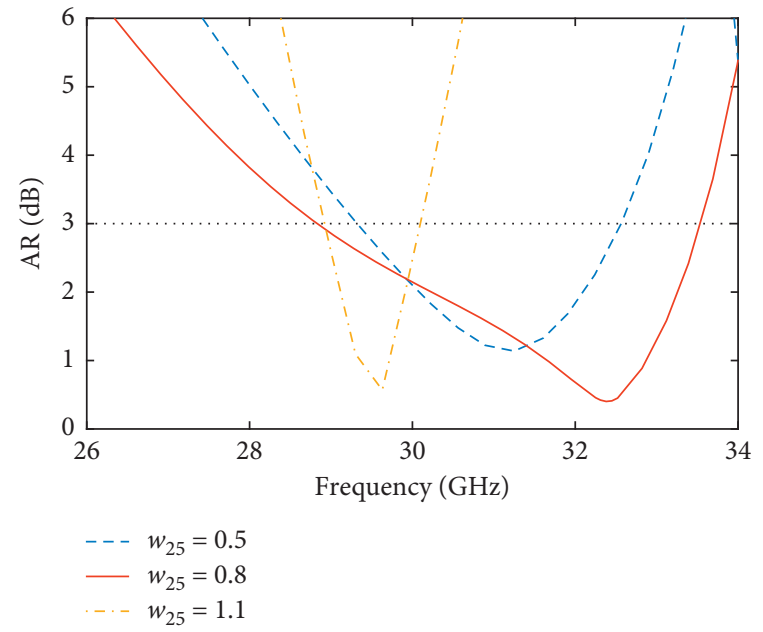

Figure 11: Effects of various $w_{25}$ on AR.

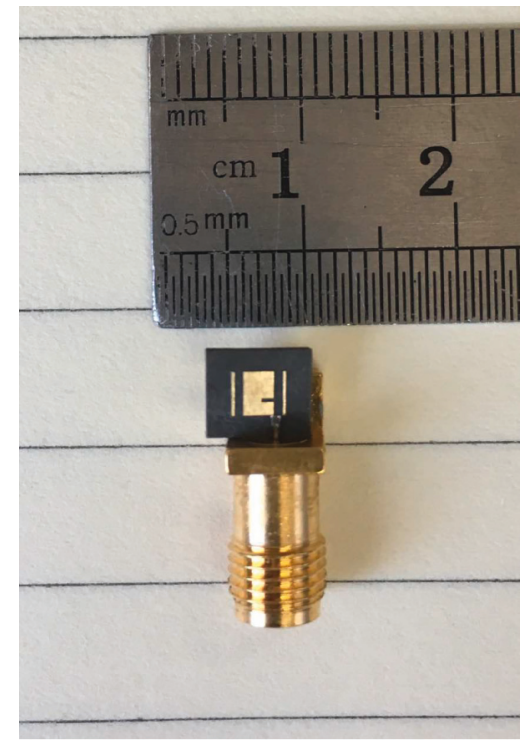

FIGURE 12: Photographs of the fabricated CP antenna showing the patch view.

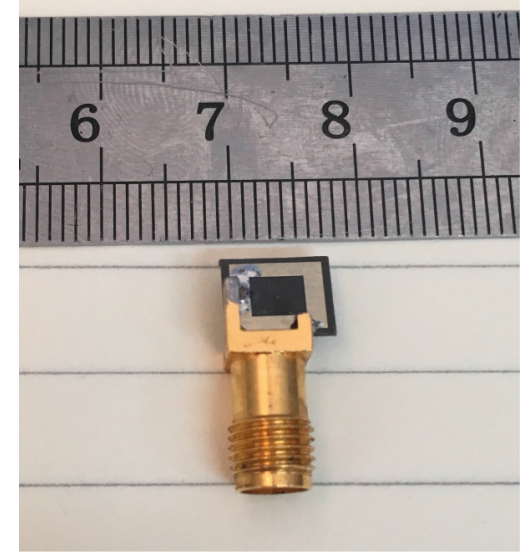

FIgURE 13: Photographs of the fabricated CP antenna showing the ground view.

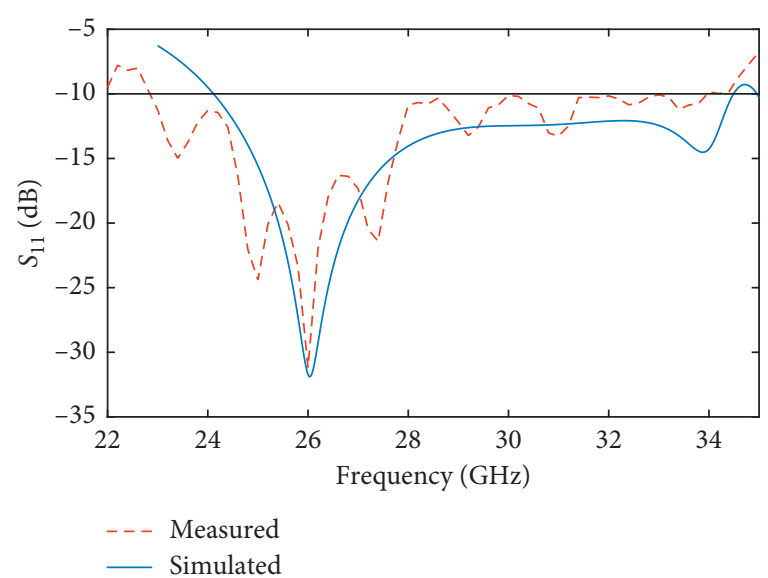

Figure 14: Simulated and measured $S_{11}$.

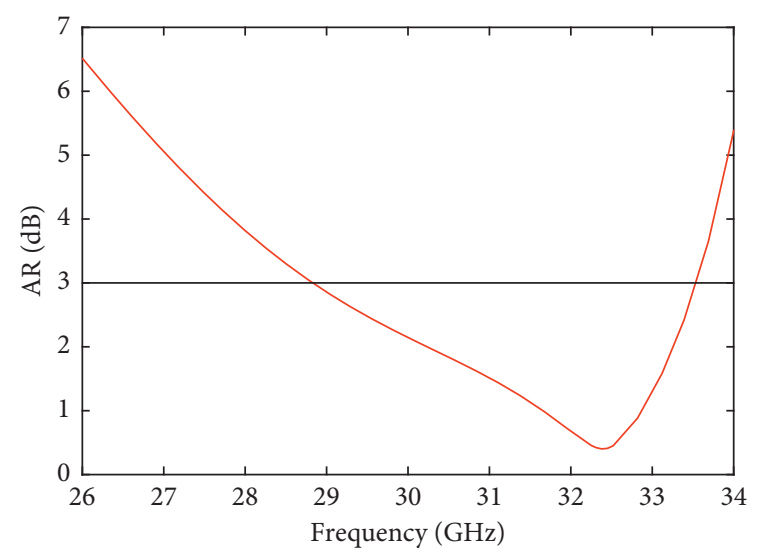

FIGURE 15: Simulated AR of the proposed antenna.

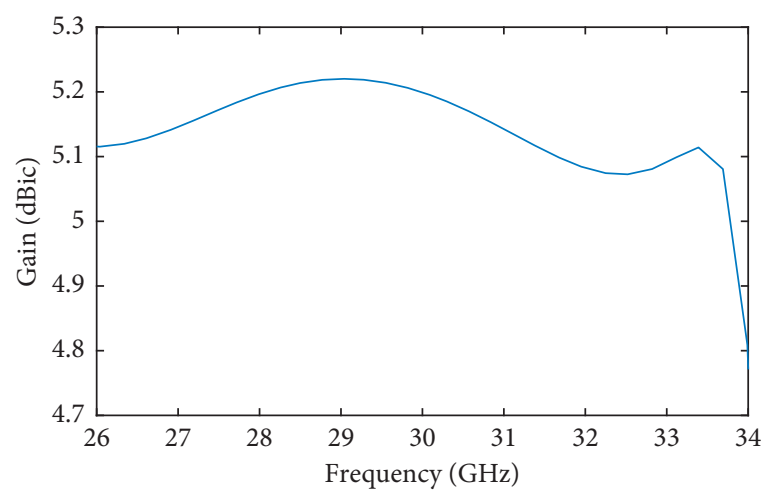

FIGURE 16: Simulated peak gain of the proposed antenna.

fabricated, and $S_{11}$ is measured to validate the design and simulated results. This antenna is tested by a vector network analyzer (AgilentN5227A). Photographs of the fabricated $\mathrm{CP}$ antenna showing the patch and ground views are shown in Figures 12 and 13, respectively.

Simulated and measured $S_{11}$ are shown in Figure 14. The simulated impedance bandwidth for $\left|S_{11}\right|<-10 \mathrm{~dB}$ is $35.43 \%$ ( 24.11 to $34.49 \mathrm{GHz}$ ). The measured IMBW for $\left|S_{11}\right|<-10 \mathrm{~dB}$ is $35.97 \%(22.8$ to $33.8 \mathrm{GHz})$, which agree with the simulated result. 

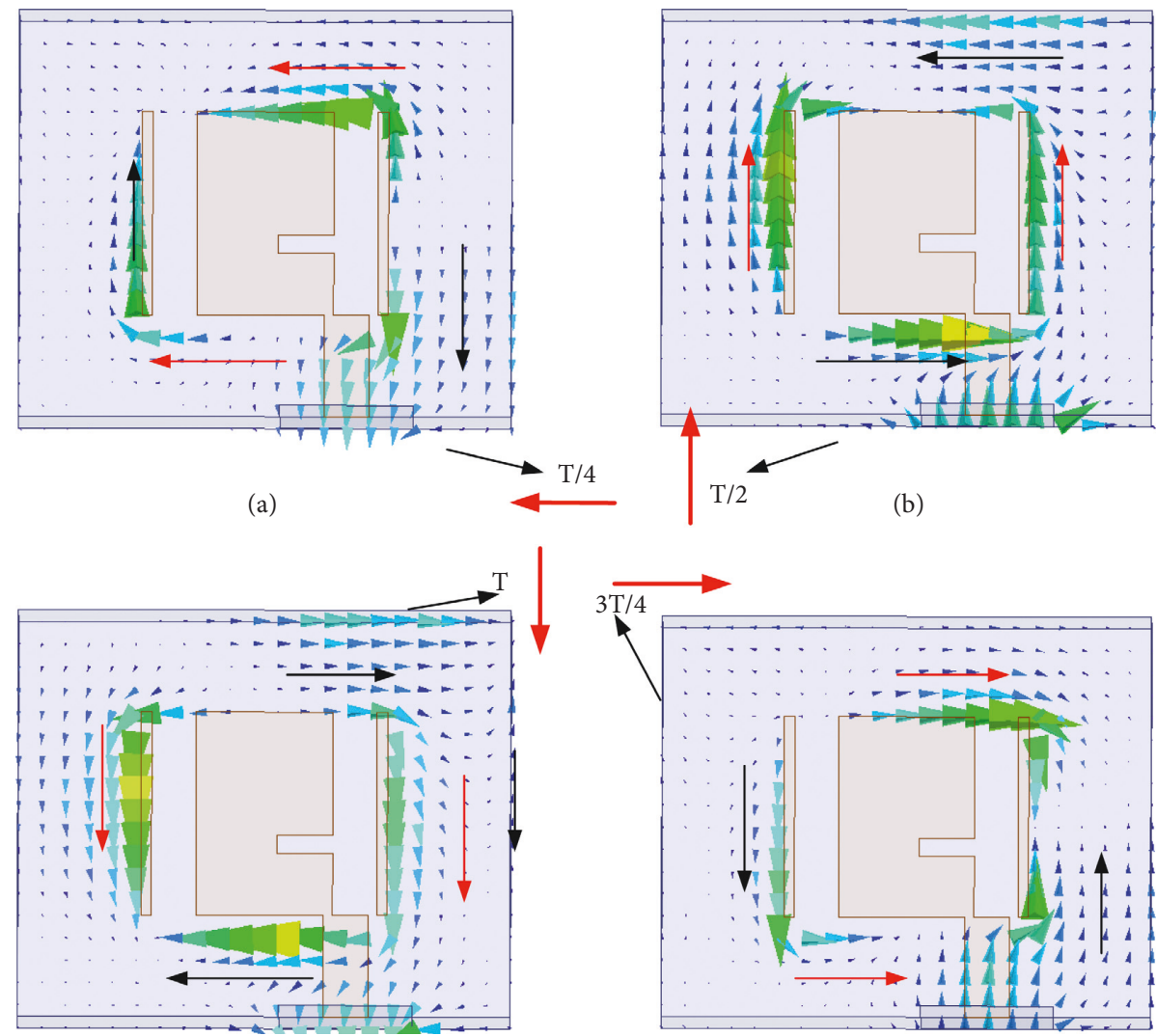

(d)

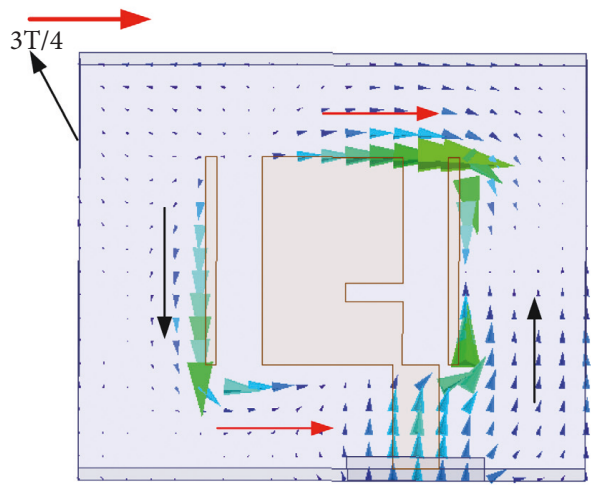

(c)

Figure 17: Simulated surface current distributions at $32.4 \mathrm{GHz}$.

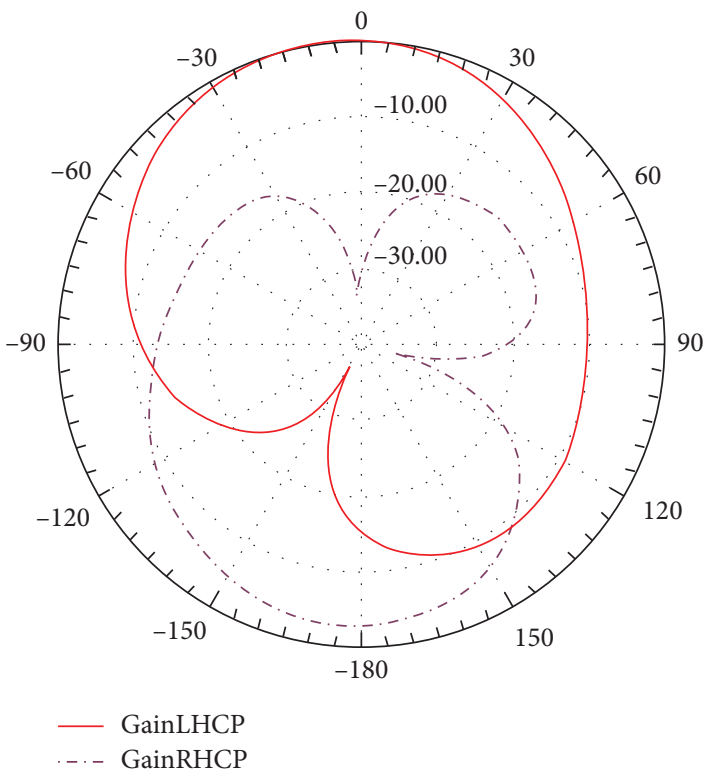

(a)

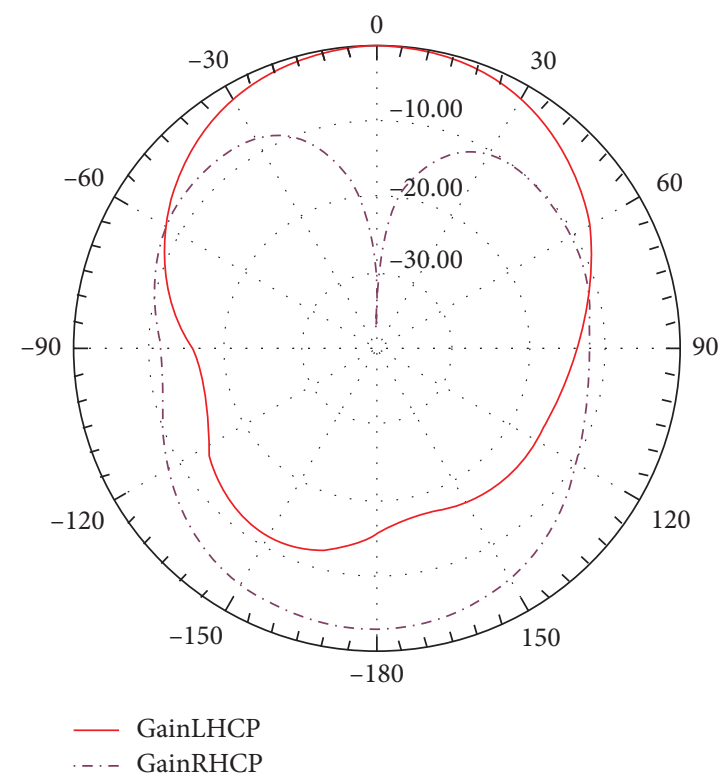

(b)

FiguRE 18: Simulated normalized radiation patterns at $32.4 \mathrm{GHz}$.

As shown in Figure 15, the simulated 3-dB ARBW is enhanced to $15.19 \%(28.77 \mathrm{GHz}$ to $33.5 \mathrm{GHz})$. In Figure 16, a peak gain between $5.08 \mathrm{dBic}$ and $5.22 \mathrm{dBic}$ is achieved at the boresight direction within 3-dB ARBW.
As shown in Figure 17, the simulated time-varying surface current distributions of ANT4 at $32.4 \mathrm{GHz}$ are illustrated to verify the generation of CP radiation. Two orthogonal resonant modes with a $90^{\circ}$ phase difference and equal amplitude can 
TABle 2: Comparison of CP Antennas at mmWave.

\begin{tabular}{lccc}
\hline ANT type & Size $\left(\lambda_{0}^{3}\right)$ & IMBW (\%) & 3-dB ARBW (\%) \\
\hline Aperture [16] & $1.58 \times 1.58 \times 0.16$ & 18 & 16.3 \\
Aperture [17] & $2 \times 1.82 \times 0.16$ & $>17.9$ & 16.3 \\
Aperture and patch [18] & $1.14 \times 1.32 \times 0.105$ & 12 & 1.3 \\
Waveguide [19] & $3.57 \times 2.07 \times 0.90$ & 10.9 & 1.1 \\
Patch [20] & $1.12 \times 0.86 \times(>0.12)$ & 35.97 & $>11.57$ \\
Proposed ANT & $0.27 \times 0.31 \times 0.047$ & 15.19 \\
\hline
\end{tabular}

achieve CP radiation. It can be observed that the proposed antenna is LHCP towards the $+z$-direction.

The normalized radiation patterns of the proposed antenna at $32.4 \mathrm{GHz}$ in $x z$ plane and $y z$ plane are shown in Figure 18.

A comparison between the proposed antenna and previous works [16-20] at mmWave frequency band is illustrated in Table 2, including the antenna type, size, impedance bandwidth (IMBW), and 3-dB ARBW. It shows the proposed antenna has a simper structure, more compact size, wider impedance bandwidth, and wider 3-dB ARBW. Additionally, because the profiles in $[16,17]$ are about three times those of the proposed antenna, the 3-dB ARBW of the proposed antenna is slightly smaller than that in $[16,17]$.

\section{Conclusion}

A novel design of Ka-band broadband CP antenna with compact structure has been presented, which is excited by a microstrip line radiator. The CP is achieved by loading a rectangular slot on the ground plane. Meanwhile, the antenna with broad IMBW and ARBW is satisfactorily realized by loading two symmetric parasitic rectangular patches paralleled to the central patch and a slit positioned to the right of the central patch. The results show that the measured impedance bandwidth of the proposed antenna for $\left|S_{11}\right|<-10 \mathrm{~dB}$ is $35.97 \%$ (22.8 to $\left.33.8 \mathrm{GHz}\right)$. Meanwhile, the simulated 3-dB ARBW is enhanced to $15.19 \%$ (28.77 GHz to $33.5 \mathrm{GHz}$ ). Meanwhile, there are about $34 \mathrm{~dB}$ difference between the simulated LHCP and RHCP components at $32.4 \mathrm{GHz}$. It is useful for $5 \mathrm{G}$ wireless applications in Ka-band.

\section{Data Availability}

The data in the HFSS used to support the findings of this study were supplied by Rongling Jian, Yueyun Chen, and Taohua Chen under license and so cannot be made freely available. Requests for access to these data should be made to Rongling Jian,jrl_ustb@126.com.

\section{Conflicts of Interest}

The authors declare that they have no conflicts of interest.

\section{Acknowledgments}

This work was supported by National Science and Technology Major Project no. 2017ZX03001021-005.

\section{References}

[1] Nasimuddin, Z. N. Chen, and X. Qing, "A compact circularly polarized cross-shaped slotted microstrip antenna," IEEE Transactions on Antennas and Propagation, vol. 60, no. 3, pp. 1584-1588, 2012.

[2] ETSI, Base Station (BS) Radio Transmission and Reception (Release 15) 3GPP TS 38.104 V15.0, ETSI, Sophia Antipolis, France, 2018.

[3] W. Roh, J.-Y. Seol, J. Park et al., "Millimeter-wave beamforming as an enabling technology for $5 \mathrm{G}$ cellular communications: theoretical feasibility and prototype results," IEEE Communications Magazine, vol. 52, no. 2, pp. 106-113, 2014.

[4] M. Akbari, H. Abo Ghalyon, M. Farahani, A.-R. Sebak, and T. A. Denidni, "Spatially decoupling of CP antennas based on FSS for 30-GHz MIMO systems," IEEE Access, vol. 5, pp. 6527-6537, 2017.

[5] J. S. Silva, E. B. Lima, J. R. Costa, C. A. Fernandes, and J. R. Mosig, "Tx-Rx lens-based satellite-on-the-move ka-band Antenna," IEEE Antennas and Wireless Propagation Letters, vol. 14, pp. 1408-1411, 2015.

[6] J. Wu, Y. Yin, Z. Wang, and R. Lian, "Broadband circularly polarized patch antenna with parasitic strips," IEEE Antennas and Wireless Propagation Letters, vol. 14, pp. 559-562, 2015.

[7] S. Fu, Q. Kong, S. Fang, and Z. Wang, "Broadband circularly polarized microstrip antenna with coplanar parasitic ring slot patch for L-band satellite system application," IEEE Antennas and Wireless Propagation Letters, vol. 13, pp. 943-946, 2014.

[8] M. S. Ellis, Z. Zhao, J. Wu, X. Ding, Z. Nie, and Q.-H. Liu, "A novel simple and compact microstrip-fed circularly polarized wide slot antenna with wide axial ratio bandwidth for C-band Applications," IEEE Transactions on Antennas and Propagation, vol. 64, no. 4, pp. 1552-1555, 2016.

[9] A. Sharma and R. K. Gangwar, "Circularly polarised hybrid Zshaped cylindrical dielectric resonator antenna for multiband applications," IET Microwaves, Antennas \& Propagation, vol. 10, no. 12, pp. 1259-1267, 2016.

[10] L. Ge, C.-Y.-G. Sim, H.-L. Su, J. Y. Lu, and C. Ku, "Single-layer dual-broadband circularly polarised annular-slot antenna for WLAN applications," IET Microwaves, Antennas \& Propagation, vol. 12, no. 1, pp. 99-107, 2017.

[11] R. Xu, J.-Y. Li, Y. X. Qi, G.-W. Yang, and J.-J. Yang, “A design of triple-wideband triple-sense circularly polarized square slot antenna," IEEE Antennas and Wireless Propagation Letters, vol. 16, pp. 1763-1766, 2017.

[12] R. Xu, J.-Y. Li, J.-J. Yang, K. Wei, and Y.-X. Qi, "A design of U-shaped slot antenna with broadband dual circularly polarized radiation," IEEE Transactions on Antennas and Propagation, vol. 65, no. 6, pp. 3217-3220, 2017.

[13] A. K. Gautam, A. Kunwar, and B. K. Kanaujia, "Circularly polarized arrowhead-shape slotted microstrip antenna," IEEE Antennas and Wireless Propagation Letters, vol. 13, pp. 471474, 2014. 
[14] D. Yu, S. X. Gong, Y. T. Wan et al., "Omnidirectional dualband dual circularly polarized microstrip antenna using TM01 and TM02 modes," IEEE Antennas and Wireless Propagation Letters, vol. 13, pp. 1104-1107, 2014.

[15] D. F. Mona, E. S. Sakomura, and D. C. Nascimento, "Circularly polarised rectangular microstrip antenna design with arbitrary input impedance," IET Microwaves, Antennas \& Propagation, vol. 12, no. 9, pp. 1532-1540, 2018.

[16] J. B. Diaaaldin, S. Liao, and Q. Xue, "High gain and low cost differentially fed circularly polarized planar aperture antenna for broadband millimeter-wave applications," IEEE Transactions on Antennas and Propagation, vol. 64, no. 1, pp. 33-42, 2016.

[17] J. B. Diaaaldin, S. Liao, and Q. Xue, "Circularly polarized planar aperture antenna for millimeter-wave applications," IEEE Transactions on Antennas and Propagation, vol. 63, no. 12, pp. 5316-5324, 2015.

[18] A. Perron, T. A. Denidni, and A. R. Sebak, "Circularly polarized microstrip/elliptical dielectric ring resonator antenna for millimeter-wave applications," IEEE Antennas and Wireless Propagation Letters, vol. 9, pp. 783-786, 2010.

[19] X. Wu, F. Yang, F. Xu, and J. Zhou, "Circularly polarized waveguide antenna with dual pairs of radiation slots at kaband," IEEE Antennas and Wireless Propagation Letters, vol. 16, pp. 2947-2950, 2017.

[20] X. Bai, S.-W. Qu, S. Yang, J. Hu, and Z.-P. Nie, "Millimeterwave circularly polarized tapered-elliptical cavity antenna with wide axial-ratio beamwidth," IEEE Transactions on Antennas and Propagation, vol. 64, no. 2, pp. 811-814, 2016.

[21] R. Garg, P. Bhartia, I. Bahl et al., Microstrip Antenna Design Handbook, Artech House, Norwood, MA, USA, 2001.

[22] F. Yang, X. X. Zhang, X. Ye, and Y. Rahmat-Samii, "Wideband E-shaped patch antennas for wireless communications," IEEE Transactions on Antennas and Propagation, vol. 49, no. 7, pp. 1094-1100, 2001. 


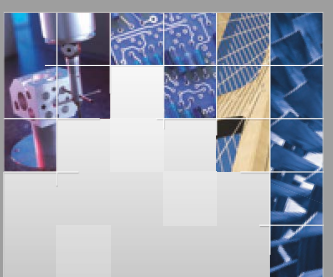

\section{Enfincering}
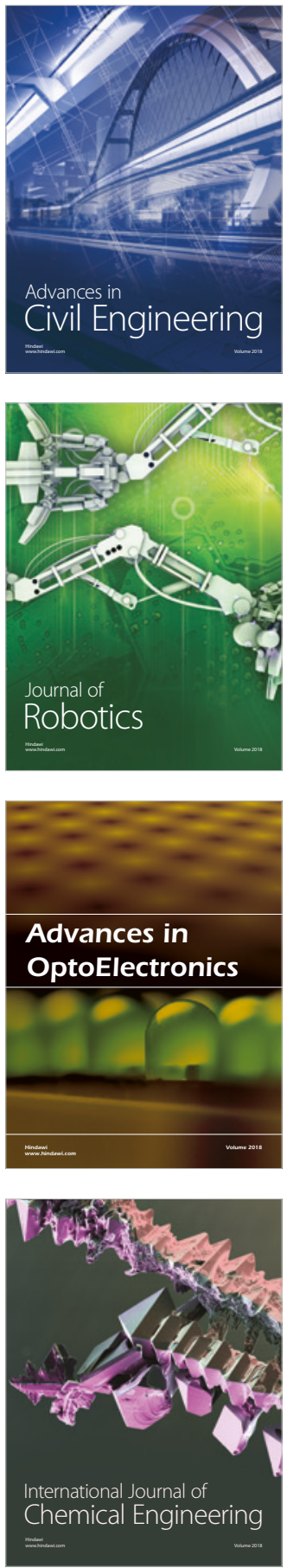

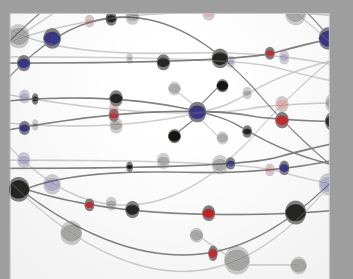

\section{Rotating \\ Machinery}

The Scientific World Journal

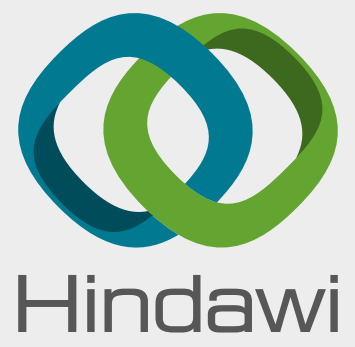

Submit your manuscripts at

www.hindawi.com
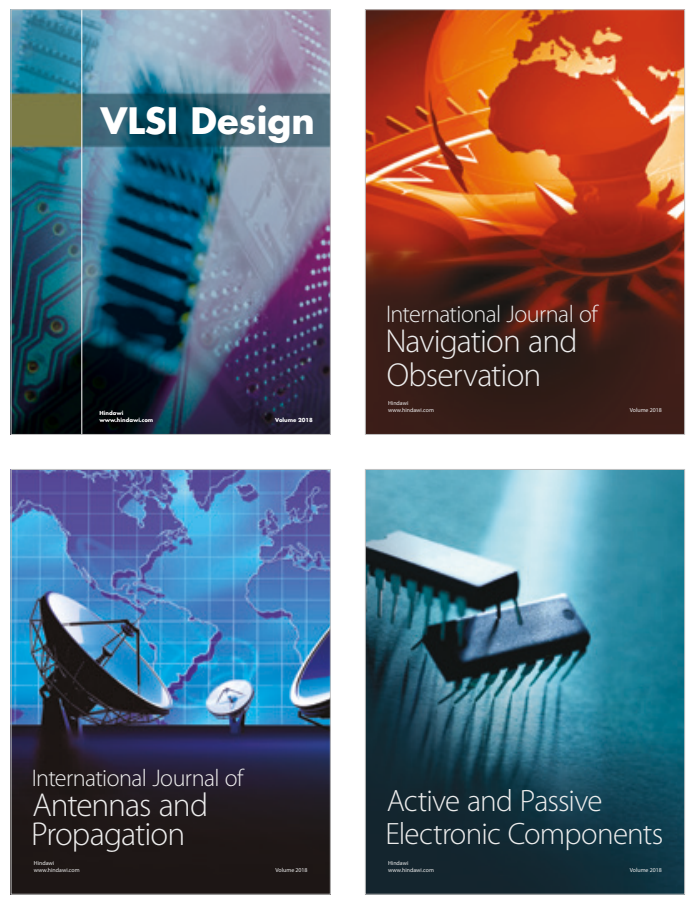
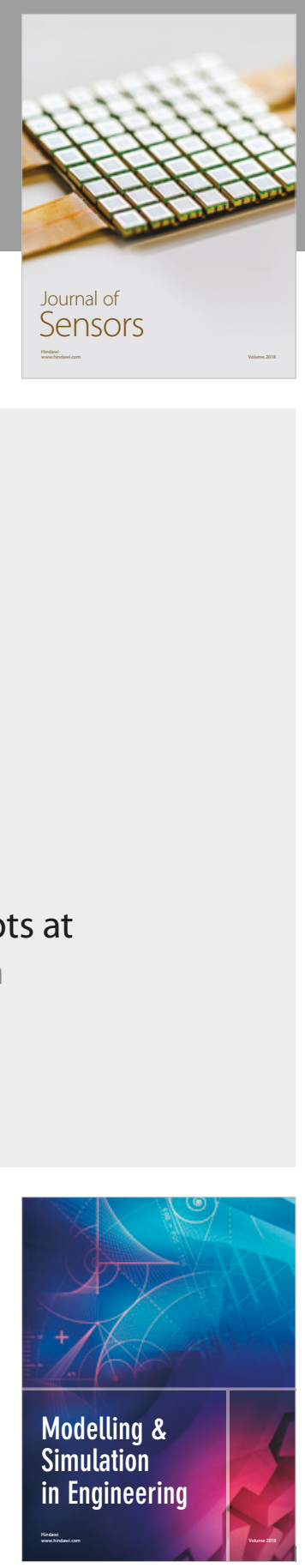

\section{Advances \\ Multimedia}
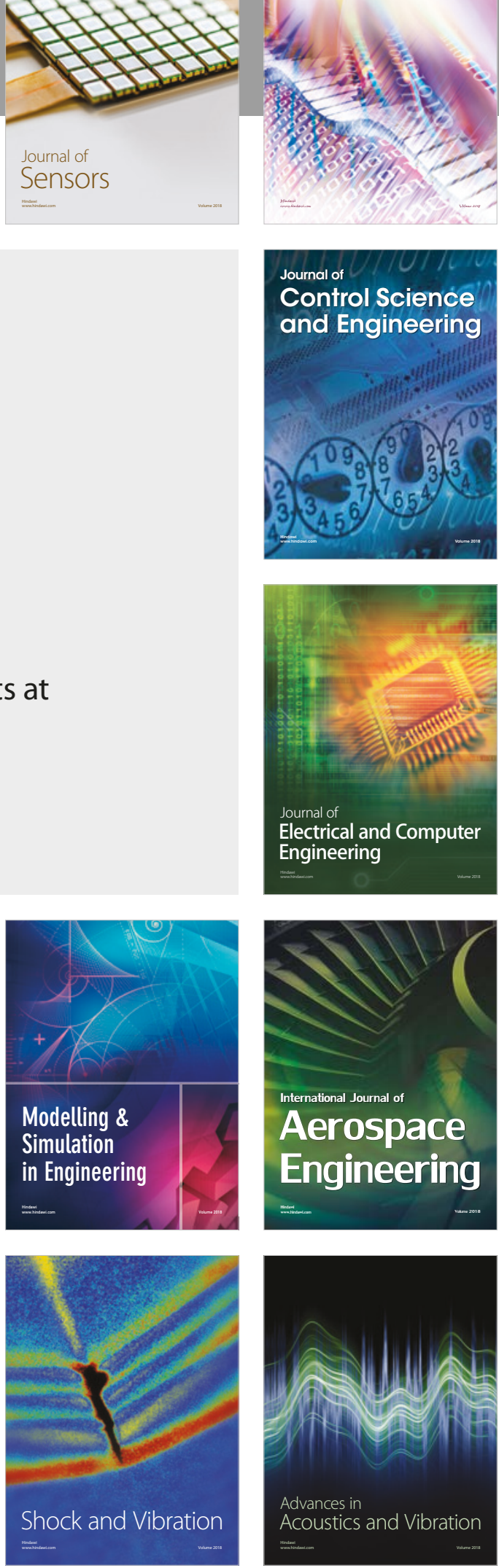